\title{
OS GRUPOS DE PESQUISA INSTITUCIONALIZADOS EM SECRETARIADO EXECUTIVO E SUA CONTRIBUIÇÃO PARA O FOMENTO DO CONHECIMENTO SECRETARIAL
}

\section{INSTITUTIONALISED RESEARCH GROUPS IN EXECUTIVE SECRETARIAT AND ITS CONTRIBUTION TO THE PROMOTION OF SECRETARIAL KNOWLEDGE}

\section{Dalila Cassagni de Mendonça Carvalho}

Bacharela em Secretariado Executivo Trilíngue pela Universidade Federal de Viçosa (UFV). E-mail: dalilacmc@gmail.com (Brasil)

\section{Lara Lúcia da Silva}

Bacharela em Secretariado Executivo Trilíngue e Mestra em Administração pela Universidade Federal de Viçosa (UFV). E-mail: laraluciads@gmail.com (Brasil) 


\title{
OS GRUPOS DE PESQUISA INSTITUCIONALIZADOS EM SECRETARIADO EXECUTIVO E SUA CONTRIBUIÇÃO PARA O FOMENTO DO CONHECIMENTO SECRETARIAL
}

\begin{abstract}
RESUMO
O objetivo deste estudo foi analisar os grupos de pesquisa em Secretariado Executivo e a sua importância para a possibilidade de construção de uma teoria própria, já que se depara com obstáculos epistemológicos na pesquisa científica secretarial. Ademais, de forma secundária, buscou-se compreender a rede social formada pelos pesquisadores da área. Para isso, utilizouse a triangulação metodológica entre os métodos qualitativo e quantitativo, bem como a aplicação de um questionário e a operacionalização de um software, que auxiliou na formação das ligações da rede social existente. Os resultados obtidos revelaram a existência de dez grupos de pesquisa na área secretarial. Verifica-se uma tendência em qualificação stricto sensu, principalmente pelo fato de que a atividade fim dos grupos é a investigação científica, demandando, assim, formação acadêmica que auxilie no crescimento do grupo e da equipe. Além disso, impasses como falta de pessoal, financiamento e literatura adequada são queixas presentes. A rede social demonstrou que $61 \%$ dos pesquisadores de Secretariado Executivo formam ligações fortes entre eles, e que 39\% constituem laços fracos, porém com potencial de expansão da rede. Pode-se chegar à conclusão de que os grupos de pesquisa ajudam a fazer com que aos poucos o número de produções científicas aumente, podendo assim embasar as atividades mais "técnicas" do Secretariado e contribuir com a formação de uma epistemologia. Combinados à formação de parcerias entre os autores, a rede social fortalece e possibilita a criação de outros grupos de estudo, atraindo cada vez mais o interesse dos estudantes.
\end{abstract}

Palavras-chave: Grupos de pesquisa. Secretariado Executivo. Redes de pesquisa. Construção do conhecimento.

\section{INSTITUTIONALISED RESEARCH GROUPS IN EXECUTIVE SECRETARIAT AND ITS CONTRIBUTION TO THE PROMOTION OF SECRETARIAL KNOWLEDGE}

\begin{abstract}
The purpose of this study was to analyze Executive Secretariat research groups and their importance in possibilities for the creation of a theory itself, since epistemological obstacles are present in the secretarial scientific research. Additionally, it sought to understand the social network of the researchers. In order to achieve this goal, a qualitative approach was used with the application of a survey and software implementation, which facilitated the formation of existing connections within the social network. The results revealed the existence of 10 research groups in the secretarial area. There is a propensity in strictosensu qualifications, mainly because the core activity of the group is the scientific research that therefore demands academic training to assist in group growth and team development. Moreover, drawbacks such as lacking sufficient staff, funding, and appropriate literature are current grievances. The social network showed that $61 \%$ of Executive Secretariat researchers form strong connections amongst each other and 39\% form weak ties, but with potential to expand the net. In conclusion, research groups gradually increase scientific production; thus allowing the more technical activities of the secretariat to contribute to the development of epistemology. Partnerships between researchers, combined with a social network, enables the
\end{abstract}


creation of other study groups, strengthening existing study groups and increasing students' interest.

Keywords: Research groups. Executive secretariat. Research networks. Creation of knowledge.

\section{INTRODUÇÃO}

A pesquisa científica figura um importante papel na vida dos estudantes, bem como em sua atuação profissional. Com as constantes mudanças do mercado e das tecnologias, dos profissionais está sendo exigido mais do que conhecimento teórico, mas também uma vivência na produção e reprodução de conhecimentos (Campos, Santos, \& Santos, 2009).

Uma das formas do acadêmico ter contato com a pesquisa científica dentro das universidades é por meio dos grupos de pesquisas. Esses têm ganhado cada vez mais espaço dentro das instituições de ensino superior. De acordo com o Conselho Nacional de Pesquisa $\mathrm{CNPq}$-, eles são caracterizados por serem compostos por pesquisadores, organizados em torno de uma hierarquia e que cujos trabalhos se direcionam em uma linha comum de pesquisa e, segundo Marafon (2008), "possibilitam aos alunos serem sujeitos no processo de construção do conhecimento" (p. 285).

No campo do Secretariado Executivo, a busca por um conhecimento mais aprofundado sobre os assuntos ligados de forma direta ou transversal à profissão está ganhando destaque nos cursos de graduação pelo Brasil. Sendo esse fenômeno algo recente, é interessante que haja estudos sobre o assunto, já que um terreno fértil em pesquisa traz como consequência debates epistemológicos de grande valor para o enriquecimento da profissão e de seus profissionais.

Além disso, de acordo com Queiroz, Silva \& Quandt (2015), houve um surgimento de novas práticas de cooperação entre os pesquisadores tendo em vista a facilidade dos atuais meios de comunicação, e este trabalho objetiva analisar a influência que esses grupos institucionalizados têm sobre a construção do conhecimento em Secretariado Executivo nas universidades, bem como averiguar as redes sociais existentes, isto é, compreender as ligações entre indivíduos a fim de identificar as conexões mais produtivas.

Este artigo traz em sua Introdução uma breve contextualização dos temas que serão tratados ao longo do texto. Em seguida, o Referencial Teórico abordará aspectos da investigação científica e dos grupos de pesquisa em Secretariado Executivo, além da Epistemologia secretarial e das Redes Sociais. Já a Metodologia explica quais foram os 
caminhos metodológicos que possibilitaram a reflexão sobre esses assuntos. $\mathrm{Na}$ Análise de Dados é possível encontrar os resultados de acordo com os critérios escolhidos e, por fim, as Considerações Finais.

\section{REFERENCIAL TEÓRICO}

\subsection{A teoria do conhecimento e a pesquisa científica no Secretariado Executivo}

Segundo Soler (2009), a epistemologia designa as ciências existentes com objetivos de entender seus valores e suas pretensões. Essa definição pode ser empregada para estudar a origem dos conhecimentos de forma geral ou aplicada em uma determinada área do saber, visando analisar as possibilidades, dentre os limites e as potências de cada uma. Já a Epistemologia da Prática Profissional pode ser definida pela Enciclopédia de Pedagogia Universitária como "o estudo do conjunto de saberes utilizado pelos profissionais em seu espaço de trabalho cotidiano para desempenhar todas as tarefas" (Morosini, 2006, p. 443).

De acordo com Nonato Júnior (2008), o Secretariado classifica-se como Ciências Sociais Aplicadas, e juntamente com alguns outros cursos dessa categoria, não possui teoria própria. Há um senso comum de que esses ramos de atuação não necessitam de uma base teórica consolidada (Nonato Júnior, 2008). Hoeller (2006) afirma que o Secretariado Executivo pode considerar-se como pertencente ao grupo das ciências factuais, pois utiliza de um método indutivo da área de humanas e que, devido a isso, é derivado de várias ciências puras, como o direito, a economia, a política etc.

Sobre essa questão, Nonato Júnior (2008) atesta que as áreas que se encontram nessa classe possuem um interesse prático, em que os resultados são aplicados e utilizados de forma imediata e que, além de terem grande atuação no mercado de trabalho, também carecem de embasamento acadêmico, filosófico e tecnológico.

Nesse sentido, Nonato Júnior (2008) argumenta que nem por isso faltam demandas intelectuais e que não há "licença" para considerar o Secretariado Executivo como meramente tecnicista. Além disso, Bíscoli e Bilert (2013) alegam que para que o desempenho de uma profissão cresça e seja bem embasado, é necessário um conhecimento próprio que acompanhe as demandas do ofício. Nesse mesmo ponto de vista é possível dialogar com Piaget (2002), o qual afirma que nos processos é necessário ampliar os sentidos e que se há uma atividade técnica, nessa pode ser sempre adicionada novos conteúdos, construindo assim estruturas adequadas. Essas afirmações vão ao encontro com a Epistemologia da Prática Profissional. 
Sabino e Marchelli (2009) incrementam a discussão afirmando que o Secretariado Executivo não se encaixa em uma categoria de ciência autônoma, pois os fundamentos da profissão na prática dependem e sempre dependeram de conhecimentos em outras áreas. A atuação do profissional se justifica sendo de assessoria e que visa atingir os objetivos organizacionais, já a práxis do Secretariado Executivo envolve a compreensão do entorno conceitual em que esses objetivos acontecem. Nonato Júnior (2008, p. 09) por sua vez, afirma:

Há, evidentemente, a necessidade de diálogo e aprendizagem constante com estas áreas, mas não na perspectiva de um conhecimento pedinte (que interage com o outro para pedir-lhe a fundamentação teórica que lhe falta) e sim na condição de um conhecimento dialógico (que se relaciona com outros para uma interdisciplinaridade de potencialidades teóricas). (Nonato Júnior, 2008, p. 9.)

Contrariando os estudos de Hoeller (2006) e Sabino e Marchelli (2009), o autor reafirma que há sim uma demanda pelo fortalecimento de uma identidade intelectual da profissão e que para isso deve-se mapear sua potência cientifica e propor uma Teoria Geral do Secretariado.

Maçaneiro e Kuhl (2013) acreditam que o caminho natural para a consolidação da pesquisa na área seria encorajar a formação acadêmica em nível stricto sensu, pois com mais pesquisadores bem qualificados e com mais títulos em níveis de mestrado e doutorado, a produção científica tornar-se-á densa e abrirá caminho para uma ciência própria.

Já na área do Secretariado Executivo é possível notar que nos últimos anos a movimentação da comunidade tem sido crescente, pois frutos como a criação de periódicos científicos, de um evento acadêmico nacional e a criação da Associação Brasileira de Pesquisa em Secretariado (ABPSEC) são muito pertinentes. (Durante \& Pontes, 2015)

Como ressalta Bíscoli e Bílert (2013), o número de publicações individuais aumentou nos últimos dez anos e não podem ser desprezadas. Segundo as autoras, encontra-se na plataforma lattes maior quantidade de secretários executivos com titulação de mestrado. Ainda assim, a área ainda carece de estudo e isso pode ser observado pelo número de revistas qualificadas pela Coordenação de Aperfeiçoamento de Pessoal de Nível Superior (Capes) (apenas três) e também pela nota recebida em cada uma delas, sendo a melhor classificada em B2. 
Sobre isso, de acordo com Pereira, Moreira e Baeta (2012), não há periódicos suficientes na área, como também não há teoria de pesquisa definida, há uma lacuna em relação aos eventos científicos em secretariado e também na bibliografia especializada.

Durante (2010) afirma que é possível perceber o baixo grau de envolvimento de alunos e professores com a prática dessa atividade pela baixa quantidade de grupos de pesquisa cadastrados no CNPq. Além disso, segundo Maçaneiro e Kuhl (2013), "falta pesquisa científica realizada pelos profissionais mestres e doutores na área específica de Secretariado Executivo" (p. 159).

A razão do pouco interesse é apontada por Pereira, Moreira \& Baeta (2012), que destacam alguns fatores como desmotivadores para o envolvimento com a pesquisa científica em Secretariado Executivo, sendo eles a falta de tempo dos professores para orientar os alunos, o desinteresse e a ausência de conscientização do discente para com a importância da pesquisa científica e também a escassez de financiamento dos órgãos competentes de cada universidade e governo.

De modo geral, reafirma-se então, a necessidade de as universidades reforçarem suas bases de ensino, pesquisa e extensão a fim de acompanharem a evolução das competências necessárias para o cotidiano do mercado de trabalho. De acordo com Pivetta, Backes, Carpes, Battistel e Marchiori (2010), o sucesso e qualidade dos profissionais oriundos das universidades dependem em grande parte do quanto eles articularam e interagiram com os três pilares do conhecimento em seu período acadêmico. E da mesma forma, é fundamental que os pesquisadores com maior titulação se voltem para área e realizem trabalhos que vão contribuir para o embasamento e reflexão da própria profissão.

\subsection{Os grupos de pesquisa institucionalizados e as redes sociais em secretariado}

Maçaneiro e Kuhl (2013) em seu trabalho "Estado da arte e o rumo do conhecimento científico em Secretariado Executivo: Mapeamento e análise de áreas de pesquisa" concluíram que para o fortalecimento da cultura de pesquisa científica em Secretariado Executivo seria preciso algumas mudanças, tais como um maior número de mestres e doutores que pudessem explorar o "caminho das pedras" e que dessa forma pudessem delimitar a cientificidade da área. Segundo as autoras, outros aspectos importantes são a criação de um mestrado específico, o surgimento e a consolidação de periódicos e eventos científicos, bem como de grupos de pesquisa. 
Para Werneck (2006), a ciência pode ser feita de diversas maneiras, com discursos científicos diferentes, não havendo, portanto, uma forma certa ou errada. Cada uma dessas variações possui estatuto e cientificidade própria que devem ser levadas em conta pelo pesquisador. $O$ processo de investigação cientifica pode ser observado em instituições públicas, órgãos do governo, instituições privadas e mais regularmente em instituições de ensino. Em cada um desses lugares a pesquisa científica se adapta para atender às necessidades encontradas no ambiente em que são produzidas. Em meio a esses ambientes os grupos de pesquisa podem se estabelecer.

De acordo com o site do $\mathrm{CNPq}$, os grupos de pesquisa se organizam de forma hierárquica em torno de um, ou eventualmente dois líderes, demais pesquisadores e por estudantes, podendo ser de pós-graduação ou não. Os líderes são escolhidos analisando critérios de disponibilidade, grau de envolvimento com a pesquisa, qualificação acadêmica e trabalhos realizados. E para Lordêlo e Sá (2015), os grupos de pesquisa contam em sua composição uma formação diversificada de pesquisadores.

De acordo com Lima e Amaral (2008), o objetivo principal desses grupos é a troca e o fomento de aprendizagens por meio da participação de seus membros nos processos de pesquisa e "no contexto das Universidades, espaço reconhecido como produtor de conhecimento, alguns estudos indicam que o trabalho em equipe melhora a quantidade e a qualidade dos artigos publicados" (Odelius \& Sena, 2009).

Conforme Krahl (2009), algumas responsabilidades são atribuídas aos membros dos grupos, como a produção textual a partir da literatura escolhida, buscas em revistas eletrônicas e também no acervo da instituição da qual fazem parte, acompanhamento das reuniões do grupo, elaboração do banco de dados e também, segundo Lima e Amaral (2008), a busca pelo financiamento e bolsas para os estudantes, publicações dos resultados obtidos e apresentação em eventos da área. Marafon (2008), por sua vez, ressalta como atividade o aprofundamento de estudos, o que segundo o autor, leva a constantes debates.

Além disso, os grupos de pesquisa se destacam ao estreitar os laços entre as universidades e as empresas. Para Garcia, Araújo, Mascarini, Santos \& Costa (2014), as instituições de ensino são consideradas fontes de ideias, conhecimento e de pessoal capacitado, que são desenvolvidos devido a um ambiente de estudos envoltos em questionamentos e análise crítica sobre a realidade de seus cursos e do mercado de trabalho. Segundo os mesmos autores, os cargos de P\&D - Pesquisa e Desenvolvimento - das organizações necessitam de vários recursos para acelerar o processo criativo e as empresas 
não hesitam em procurar os grupos de pesquisa que mais se destacam, seja pela qualidade do conteúdo publicado ou pelo renome da universidade em seus campos de ação.

Portanto, a participação dos estudantes no processo de pesquisa propicia um momento de troca de experiências dentro e fora da universidade, onde é possível agregar conhecimentos e inseri-los na prática profissional. Esse exercício torna-se então ainda mais educativo e convida o aluno a ser sujeito construtivo desse processo (Krahl et al., 2009), começando antecipadamente a desenvolver o seu potencial crítico e observador e formando-se um profissional disposto a refletir a realidade que o cerca.

Nesse contexto, o compartilhamento das bagagens científicas de cada pesquisador pode ser feito fora dos limites da instituição no qual esteja vinculado e isso influencia o processo de criação do conhecimento. Essa conexão estabelecida é chamada de rede social (Rossoni, Hocayen-Da-Silva \& Ferreira Júnior, 2008). Maia e Caregnato (2008) acrescentam que as redes sociais propiciam aos pesquisadores uma visão mais abrangente da relação entre as partes, diferenciando-se de análises com perspectivas individuais.

Segundo Rossoni, Hocayen-da-Silva \& Ferreira Júnior (2008), fazem parte dessa rede indivíduos, organizações ou países que são interligados por um mesmo interesse ou parcerias, e que dessa forma recebem o nome de atores sociais. De acordo com os mesmos autores, essas redes objetivam pensar e qualificar essas ligações e a atuação desses agentes.

Dentro dessa malha é possível identificar os sujeitos que se ligam a dois atores (díades) e outros que são formadas por três ou mais (tríades). Essas associações ocupam um lugar mais central e estratégico em uma rede e infere-se que as ideias desses participantes tenham mais difusão e que sejam mais influentes em seu campo de atuação. São conexões formadas por laços fortes (Rossoni, Hocayen-Da-Silva, \& Ferreira Júnior, 2008; Nascimento \& Beureu, 2011).

Os laços fracos, por sua vez, são caracterizados por uma associação simples, ou seja, não se relacionam frequentemente e participam de elos menos densos. São localizados na área periférica da rede (Nascimento \& Beureu, 2011; Souza et al, 2008). Porém, segundo Granovetter (1973), são indispensáveis para expandir a integração com a rede e impulsionar novas oportunidades de inovação, já que não fazem parte do grupo homogêneo dos laços fortes.

A averiguação desses laços para a área é fundamental para entender quem são os participantes mais ativos, isto é, quais universidades realizam mais trabalhos científicos com a colaboração de pesquisadores de outras instituições e sugerir a integração entre os grupos a fim de promover a criação conjunta. De acordo com Schmidt, Cielo \& Sanches (2011) essa 
estratégia é útil para as áreas em desenvolvimento científico recente ou que possuem intenção no aumento da produtividade acadêmica, como é o caso do Secretariado Executivo. Além disso, as redes são de natureza interdisciplinar e, por isso, se assemelham à área secretarial.

\section{METODOLOGIA}

Para esta pesquisa foi utilizada a triangulação metodológica, já que, segundo Duarte (2009), caracteriza-se pelo emprego de "múltiplos métodos para estudar um determinado problema de investigação" (p.12). Por meio da pesquisa qualitativa busca-se a compreensão do cenário atual, do funcionamento e as perspectivas dos grupos de pesquisa em Secretariado Executivo. Além disso, segundo Corbin e Strauss (2015), é um método interpretativo e dinâmico que permite ao pesquisador ser mais flexível. Já com a pesquisa quantitativa buscou-se mensurar os dados dos respondentes, a fim de quantificar e analisar o panorama das redes sociais na área de secretariado no Brasil. Para Gerhardt e Silveira (2009) esse método "utiliza procedimentos estruturados e instrumentos formais para coleta de dados" e analisa os resultados através da estatística ou de outras ferramentas matemáticas” (p. 34). Ademais, caracteriza-se por ser uma pesquisa exploratória, pois para Gil (2007), ela tem como objetivo oferecer maior familiaridade com a problemática em questão, com vistas a torná-la mais clara ou facilitar a construção de hipóteses.

A pesquisa foi dividida em dois momentos. Primeiramente, foi utilizado o método survey, que, segundo Freitas, Oliveira, Saccol \& Moscarola (2000), é adequada quando as perguntas se agrupam em "o quê?", "por quê?" e "como?" para a coleta de dados primários, feita por meio de questionário que, Gunther (2003) classifica como principal instrumento para a verificação por amostragem. As perguntas tinham por finalidade conhecer o perfil dos membros, dos grupos e como em hipótese averiguar a influência desses na criação de uma epistemologia própria na área secretarial. Elas foram enviadas por e-mail aos líderes dos dez grupos de pesquisa existentes em Secretariado Executivo no Brasil e ficaram à disposição para serem respondidas pelos membros dos grupos entre setembro e dezembro de 2015. Obteve-se retorno de sete respondentes, o que dificultou uma análise mais completa das respostas.

O instrumento de coleta de dados era formado por 16 questões, entre elas perguntas fechadas e uma aberta, sendo que em relação à questão dissertativa, foi feita uma análise das respostas de acordo com o referencial teórico utilizado. Nas perguntas fechadas utilizou-se a escala Likert, pois conforme Mattar (2005), é possível verificar atitudes e tendências por 
intermédio de afirmativas e a partir disso conhecer o grau de concordância e discordância dos respondentes sobre a problemática em análise.

Para complementar as investigações acerca da pesquisa no Secretariado Executivo, foi realizado um estudo das redes sociais, com base da coleta de dados feita a partir das informações de autoria dos artigos publicados nas revistas catalogadas no portal ABPSEC. A análise baseou-se na instituição onde os autores cursaram ou cursam sua graduação, sendo ela em Secretariado Executivo ou não, de acordo com as informações encontradas na Plataforma Lattes. Esse parâmetro foi estabelecido tendo em vista o grau de titulação acadêmica em comum. Foi escolhida uma análise temporal de dois anos (entre 2014 e 2015) a fim de analisar o panorama mais recente das redes de pesquisa, bem como pelo fato do ano de 2014 ter apresentado um aumento significativo de grupos de pesquisa se comparado com os anos anteriores. Ao todo foram analisados 71 artigos.

Após compilação, o software NetMiner ${ }^{\circledR}$ (versão 4.0) foi utilizado no cruzamento e obtenção dos dados. Assim, por meio do questionário e da análise das redes sociais, foi possível traçar um panorama dos grupos de pesquisa em Secretariado Executivo no Brasil nos últimos anos.

\section{ANÁLISE DE DADOS}

\subsection{Grupos de pesquisa em Secretariado Executivo: algumas informações}

Em consonância aos objetivos deste trabalho e ao que foi exposto, é necessário conhecer a realidade dos grupos de pesquisa em Secretariado. Existem 134 cursos de graduação na área no Brasil (ABPSEC, 2016), entre universidades públicas e privadas, e, no entanto, apenas dez grupos de pesquisa institucionalizados. Com essas informações é possível observar que ainda é pequeno o número de universidades envolvidas com essa atividade, porém verifica-se um aumento gradativo destes grupos institucionalizados.

Dentro desses grupos é possível verificar, de acordo com o portal online do CNPq, que sete possuem líderes com título máximo de doutorado e os demais com titulação máxima em nível de mestrado.

Conforme os Quadros 1 e 2, pode-se conhecer a atual situação desses grupos na área secretarial. 
Quadro 1: Caracterização dos Grupos de Pesquisa em Secretariado Executivo que se encontram cadastrados no CNPq.

\begin{tabular}{|c|c|c|c|c|c|}
\hline Nome & Região/Ano & $\begin{array}{l}\text { Número de } \\
\text { linhas de } \\
\text { pesquisa }\end{array}$ & Pesquisadores & Estudantes & Técnicos \\
\hline $\begin{array}{lr}\text { Grupo de } & \text { pesquisa em } \\
\text { Secretariado } & \text { Executivo } \\
\text { Bilíngue } & \end{array}$ & $\mathrm{Sul} / 2002$ & 4 & 19 & 1 & 0 \\
\hline $\begin{array}{lccc}\text { Grupo de Estudos em } \\
\text { Secretariado Executivo }\end{array}$ & $\mathrm{Sul} / 2007$ & 1 & 2 & 0 & 0 \\
\hline $\begin{array}{l}\text { Grupo de Pesquisas } \\
\text { Interdisciplinares } \\
\text { Secretariado }\end{array}$ & Nordeste/2009 & 5 & 10 & 6 & 0 \\
\hline $\begin{array}{l}\text { Gestão do conhecimento } \\
\text { nas Ciências Sociais } \\
\text { Aplicadas }\end{array}$ & $\mathrm{Sul} / 2009$ & 2 & 20 & 19 & 0 \\
\hline $\begin{array}{l}\text { Núcleo de Pesquisa de } \\
\text { Estudos em Secretariado } \\
\text { Executivo e áreas afins }\end{array}$ & $\begin{array}{l}\text { Centro- } \\
\text { Oeste/2011 }\end{array}$ & 7 & 4 & 2 & 0 \\
\hline $\begin{array}{l}\text { Grupo de Estudos e } \\
\text { Pesquisas em Secretariado } \\
\text { Executivo }\end{array}$ & Nordeste/2014 & 6 & 6 & 14 & 3 \\
\hline $\begin{array}{l}\text { Observatório Latino } \\
\text { Americano de Pesquisa em } \\
\text { Secretariado Executivo }\end{array}$ & Nordeste/2014 & 0 & 3 & 3 & 0 \\
\hline 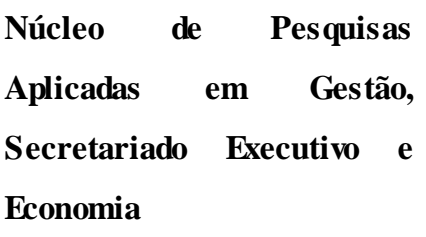 & Norte/2014 & 6 & 7 & 5 & 1 \\
\hline $\begin{array}{l}\text { Núcleo Interdisciplinar de } \\
\text { Estudos em Secretariado } \\
\text { Executivo }\end{array}$ & Sudeste/2014 & 4 & 3 & 6 & 1 \\
\hline $\begin{array}{l}\text { Grupo de Pesquisa em } \\
\text { Secretariado Executivo } \\
\text { Bilíngue (GEPSEB) }\end{array}$ & $\mathrm{Sul} / 2014$ & 2 & 3 & 0 & 0 \\
\hline & Totais & 37 & 77 & 56 & 5 \\
\hline
\end{tabular}

Fonte: Elaborado pelos autores com informações do Diretório dos Grupos de Pesquis a no Brasil, 2016. 
Ao observá-lo, pode-se verificar que, em 2002, surgiu na região Sul o primeiro grupo de pesquisa em Secretariado Executivo institucionalizado e, após cinco anos, surgiram outros dois, em regiões diferentes, Sul e Nordeste. Em 2009, mais dois grupos surgiram e, em 2011, apenas um. Nota-se que o ano de 2014 foi muito importante para o crescimento da quantidade desses grupos, tendo sido criado outros cinco. O Quadro 1 também mostra o número de pesquisadores envolvidos em cada grupo (podendo exercer diversas funções), além da quantidade de linhas de pesquisa adotadas.

De acordo com a situação dos grupos no portal online do $\mathrm{CNPq}$, verifica-se que um dos grupos da região Nordeste, fundado em 2007, foi excluído possivelmente ao fim de 2015, como consta em sua última atualização. As razões para o término do grupo não foram disponibilizadas.

Em relação à localização, verifica-se que as regiões Sul e Nordeste contam com a maior parte deles, representando juntas $63 \%$ do total, isso se deve pela maior concentração de cursos em Secretariado Executivo nessas localidades, conforme Figura 1.

\section{Figura 1: Localização dos grupos de pesquisa}

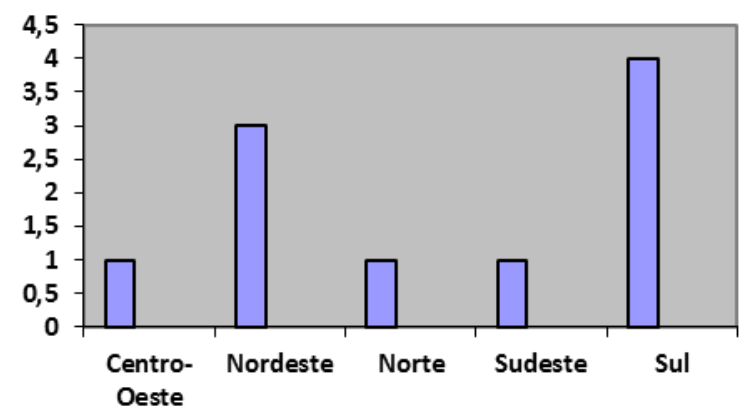

Fonte: Elaborada pelos autores com informações da ABPSEC, 2016.

Outro dado relevante é a quase não utilização, seja por falta de mão de obra ou de necessidade, dos técnicos que, de acordo com o portal do CNPq, têm como função ajudar os pesquisadores em suas atividades de pesquisa, podendo elas variarem conforme o campo de ação. Observa-se que sete dos dez grupos analisados não contam com esse tipo de ajuda.

Para um maior aprofundamento no tema, o Quadro 2 detalha as linhas de pesquisa trabalhada por cada grupo.

Quadro 2: Linhas de pesquisa dos grupos de pesquisa em Secretariado Executivo e áreas predominantes. 


\begin{tabular}{|c|c|c|}
\hline Nome & Linha de Pesquisa & $\begin{array}{l}\text { Área } \\
\text { predominante }\end{array}$ \\
\hline $\begin{array}{l}\text { Grupo de pesquisa em } \\
\text { Secretariado } \\
\text { Executivo Bilíngue }\end{array}$ & $\begin{array}{l}\text { Assessoria e gestão organizacional; } \\
\text { empreendedorismo, } \\
\text { internacionalização; gestão socioambiental } \\
\text { nas organizações; língua estrangeira } \\
\text { moderna }\end{array}$ & $\begin{array}{l}\text { Ciências Sociais } \\
\text { Aplicadas; } \\
\text { Administração }\end{array}$ \\
\hline $\begin{array}{l}\text { Grupo de Estudos em } \\
\text { Secretariado } \\
\text { Executivo }\end{array}$ & $\begin{array}{l}\text { Formação e atuação do profissional de } \\
\text { Secretariado }\end{array}$ & $\begin{array}{l}\text { Ciências Sociais } \\
\text { Aplicadas; } \\
\text { Administração }\end{array}$ \\
\hline $\begin{array}{l}\text { Grupo de Pesquisas } \\
\text { Interdisciplinares em } \\
\text { Secretariado }\end{array}$ & $\begin{array}{l}\text { Educação; gestão e } \text { organizações; } \\
\text { linguagens; sociologia; tecnologias }\end{array}$ & $\begin{array}{l}\text { Ciências Sociais } \\
\text { Aplicadas; } \\
\text { Administração }\end{array}$ \\
\hline $\begin{array}{lr}\text { Gestão } & \text { do } \\
\text { conhecimento } & \text { nas }\end{array}$ & $\begin{array}{l}\text { Ciência da assessoria e ciência da } \\
\text { informação: } \\
\text { compartilhamento }\end{array}$ & $\begin{array}{l}\text { Ciências Sociais } \\
\text { Aplicadas; }\end{array}$ \\
\hline $\begin{array}{l}\text { Ciências } \quad \text { Sociais } \\
\text { Aplicadas }\end{array}$ & $\begin{array}{l}\text { interdisciplinar do conhecimento; gestão do } \\
\text { conhecimento em Secretariado Executivo }\end{array}$ & $\begin{array}{l}\text { Ciência } \\
\text { Informação }\end{array}$ \\
\hline $\begin{array}{l}\text { Núcleo de Pesquisa de } \\
\text { Estudos em } \\
\text { Secretariado } \\
\text { Executivo e áreas afins }\end{array}$ & $\begin{array}{l}\text { Administração empresarial; administração, } \\
\text { marketing e ciência da comunicação; estudo } \\
\text { socioeconômico e pesquisa de mercado e } \\
\text { opinião; formação e atuação do profissional } \\
\text { de secretariado; gestão empresarial; língua } \\
\text { estrangeira moderna; pesquisa em } \\
\text { Secretariado Executivo }\end{array}$ & $\begin{array}{l}\text { Ciências Sociais } \\
\text { Aplicadas; } \\
\text { Administração }\end{array}$ \\
\hline $\begin{array}{l}\text { Grupo de Estudos e } \\
\text { Pesquisas } \\
\text { Secretariado } \\
\text { Executivo }\end{array}$ & $\begin{array}{l}\text { Consultoria em secretariado; educação em } \\
\text { Secretariado } \quad \text { Executivo; estudos } \\
\text { organizacionais e gestão secretarial; gestão } \\
\text { de pessoas e empreendedorismo; gestão } \\
\text { secretarial e assessoria executiva; pesquisa } \\
\text { em Secretariado Executivo }\end{array}$ & $\begin{array}{l}\text { Ciências Sociais } \\
\text { Aplicadas; } \\
\text { Administração }\end{array}$ \\
\hline $\begin{array}{lr}\text { Observatório } & \text { Latino- } \\
\text { Americano } & \mathrm{de} \\
\text { Pesquisa } & \mathrm{em}\end{array}$ & - & $\begin{array}{l}\text { Ciências Sociais } \\
\text { Aplicadas; }\end{array}$ \\
\hline
\end{tabular}




\begin{tabular}{|c|c|c|}
\hline $\begin{array}{l}\text { Secretariado } \\
\text { Executivo }\end{array}$ & & \\
\hline $\begin{array}{l}\text { Núcleo de Pesquisas } \\
\text { Aplicadas em Gestão, } \\
\text { Secretariado } \\
\text { Executivo e Economia }\end{array}$ & 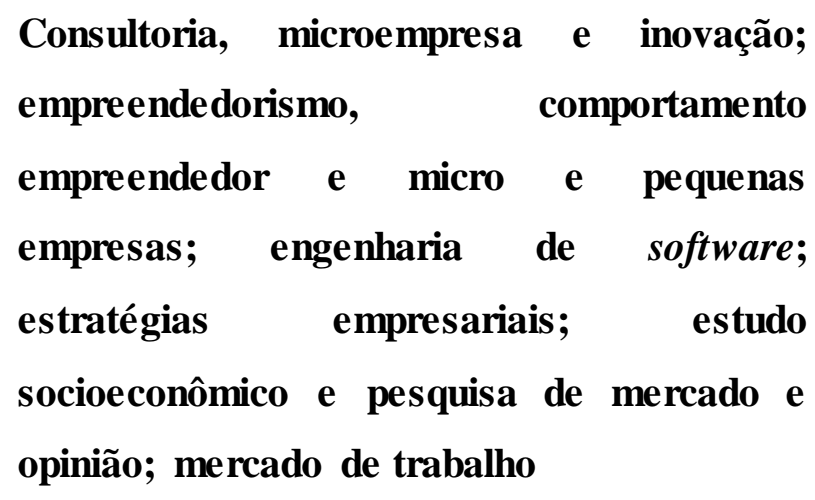 & $\begin{array}{l}\text { Ciências Sociais } \\
\text { Aplicadas; } \\
\text { Administração }\end{array}$ \\
\hline $\begin{array}{l}\text { Núcleo Interdisciplinar } \\
\text { de Estudos em } \\
\text { Secretariado } \\
\text { Executivo }\end{array}$ & 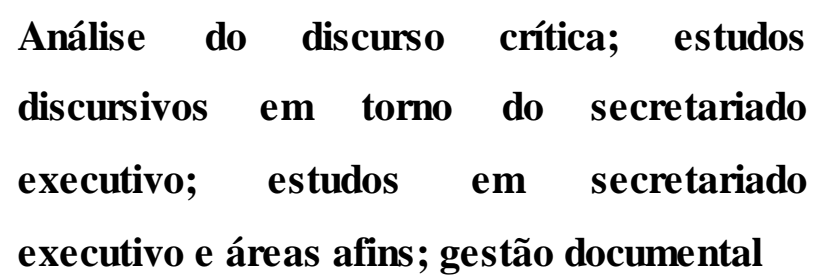 & $\begin{array}{l}\text { Ciências Sociais } \\
\text { Aplicadas; } \\
\text { Administração }\end{array}$ \\
\hline $\begin{array}{l}\text { Grupo de Pesquisa em } \\
\text { Secretariado } \\
\text { Executivo Bilíngue }\end{array}$ & $\begin{array}{l}\text { Gestão secretarial; línguas estrangeiras } \\
\text { modernas e língua portuguesa }\end{array}$ & $\begin{array}{l}\text { Ciências Sociais } \\
\text { Aplicadas; } \\
\text { Administração }\end{array}$ \\
\hline
\end{tabular}

Fonte: Elaborado pelos autores com informações do Diretório dos Grupos de Pesquisa no Brasil, 2016.

Com essas informações observa-se que as áreas de estudo predominantes são em sua maioria em Ciências Sociais Aplicadas e Administração e dentre elas, nas linhas de pesquisa, nota-se uma maior concentração dos estudos em Linguagens, Gestão Secretarial e Administração.

\subsection{Análise do questionário: os grupos de pesquisa}

Observa-se que do total dos respondentes, $72 \%$ dos membros possuem menos de 30 anos, $14 \%$ estão entre 30 e 40 anos e outros $14 \%$ possuem mais de 50 anos, evidenciando que grande parte dos integrantes dos grupos é jovem. Ainda sobre o perfil geral, 85\% são do sexo feminino e $15 \%$ do sexo masculino, e $58 \%$ do total de participantes possuem Pós-graduação stricto sensu - Mestrado, 14\% ainda não se graduaram, 14\% possuem graduação completa e, por fim, 14\% apresentam título de Pós-doutorado. Esses dados demonstram que apesar de o número de pós-graduados em Secretariado Executivo ser pequeno, verifica-se uma tendência em qualificação stricto sensu considerando os grupos de pesquisa, principalmente pelo fato de 
que a atividade fim dos grupos é a pesquisa científica, demandado, assim, formação acadêmica que auxilie no crescimento da equipe.

Em relação ao tempo de atuação, $28 \%$ dos respondentes fazem parte do grupo por pelo menos um ano, sendo que a maior parte $(42 \%)$ participa por um período que varia entre três a cinco anos, evidenciando um vínculo mais duradouro.

Os membros em um grupo de pesquisa podem assumir papéis diversos onde atuam, conforme Figura 2.

Figura 2: Atuação no grupo de pesquisa.

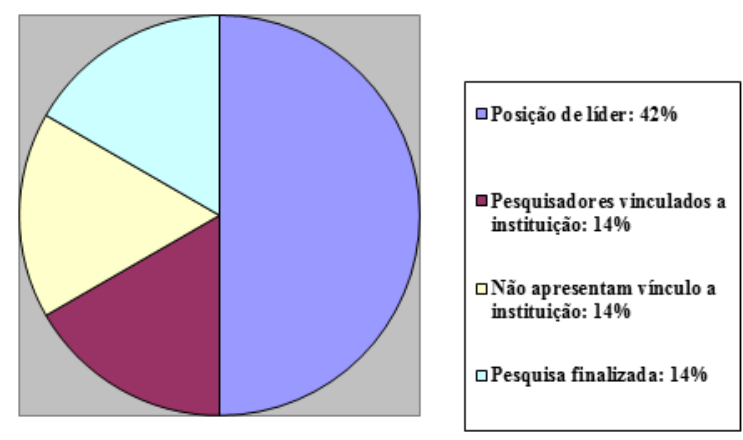

Fonte: Elaborada pelos autores com informações do Diretório dos Grupos de Pesquisa no Brasil, 2016.

Como dito por Lordêlo e Sá (2015), a interação entre membros de diversos níveis de formação é algo que se passa na composição dos grupos, mas esse pode ser encarado como um ponto positivo, já que por meio do diálogo com pessoas com diversas experiências outros olhares sobre um mesmo tema podem surgir.

Os grupos de pesquisa podem se organizar de formas distintas, e no que concerne a essa questão, 57 \% concordam parcialmente com a afirmativa de que os encontros ocorrem com periodicidade definida, já $43 \%$ concordam totalmente que há regularidade nos grupos em que participam.

Quando perguntados se o grupo de pesquisa recebe auxilio financeiro da universidade na qual está vinculado, $86 \%$ discordam totalmente contra $14 \%$ que discordam parcialmente o que expõe o baixo investimento por meio das entidades mantenedoras. Sobre o subsídio proveniente dos órgãos de fomento à pesquisa, $71 \%$ concordam totalmente e $14 \%$ concordam parcialmente que recebem ajuda. Segundo Pereira, Moreira \& Baeta (2012), o financiamento é um fator de motivação para que os discentes se envolvam com a pesquisa científica, influenciando assim na quantidade e qualidade das produções na área. 
Nessa perspectiva, os integrantes foram questionados se o grupo de pesquisa do qual fazem parte são capazes de estimulá-los a continuar ou mesmo iniciar uma carreira no meio acadêmico científico, conforme Figura 3:

Figura 3: Motivação em continuar/iniciar uma carreira no meio acadêmico-científico.
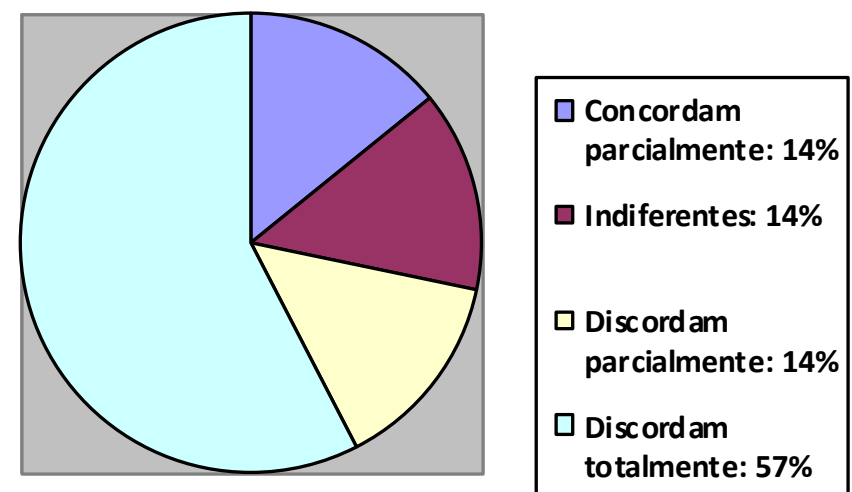

Fonte: Dados obtidos pelos autores, 2015.

Observa-se que mais da metade das respostas não são favoráveis a essa premissa. Isso pode ter sido causado por diversos fatores e alguns deles podem ser verificados nas respostas dos participantes. Quando perguntados sobre as maiores dificuldades enfrentadas, constata-se que $57 \%$ se deparam com a falta de auxilio financeiro para participação em eventos da área, sendo essa condição desmotivadora para os respondentes. Outra causa recorrente é relacionada aos recursos humanos. É possível citar das respostas abertas: "Os encontros não conseguem reunir todos os membros e a participação de todos fica comprometida" e "Reduzido número de participantes". Além disso, a pouca literatura e a pouca aceitação de pesquisas sobre Secretariado em periódicos de áreas correlatas também foram mencionados. Resultados parecidos foram encontrados por Pereira, Moreira \& Baeta (2012) no artigo "Fatores motivacionais para pesquisa na área de Secretariado Executivo das IFES brasileiras", o que expõe que a realidade dos grupos demonstra os mesmos problemas.

Sobre a importância na vida pessoal, depreende-se que 57\% relatam que os grupos contribuem para o desenvolvimento pessoal de forma positiva, outros $29 \%$ concordam parcialmente, sendo que $14 \%$ são indiferentes a essa afirmativa. Já no crescimento profissional, $71 \%$ concordam totalmente e $29 \%$ concordam parcialmente que os grupos de estudos auxiliam de forma benéfica os respondentes. Com isso, infere-se que apesar de os 
membros reconhecerem o valor dos grupos no âmbito individual e profissional, os empecilhos muitas vezes são superiores aos benefícios, fazendo com que eles não encontrem estímulo suficiente para continuar realizando pesquisas científicas.

E, por fim, no que concerne à construção do conhecimento científico e ao crescimento profissional da área secretarial, $86 \%$ concordam totalmente que o grupo pode ser responsável por essa melhora, em oposição à $14 \%$ que discordam parcialmente. Com isso, consegue-se assimilar que a grande maioria assente com a capacidade dessa ferramenta de pesquisa ofertar bons resultados à área. Consoante as ideias de Hoeller (2006), é da universidade que surge o interesse em aprofundar os estudos sobre as ciências, bem como da própria profissão. Com essas informações é possível perceber que em geral os integrantes reconhecem que fazer parte de um grupo de pesquisa é importante tanto para os próprios membros quanto para sua área e seu trabalho. Porém, as universidades de modo de geral não investem, seja financeiramente ou com estrutura adequada, de maneira suficiente para atender às demandas para o contínuo avanço desses grupos.

\subsection{Análise da construção das redes sociais em Secretariado Executivo}

A realização de um estudo sobre as redes sociais em Secretariado foi feita com o intuito de complementar as informações obtidas sobre os grupos de pesquisa e propiciar uma visão mais ampla sobre o tema.

$\mathrm{Na}$ figura 4, observa-se a rede das relações interinstitucionais em Secretariado Executivo e, por meio dela, é possível identificar algumas características sobre a cooperação científica na concepção de pesquisas na área.

Figura 4: Visão geral da rede social em Secretariado. 


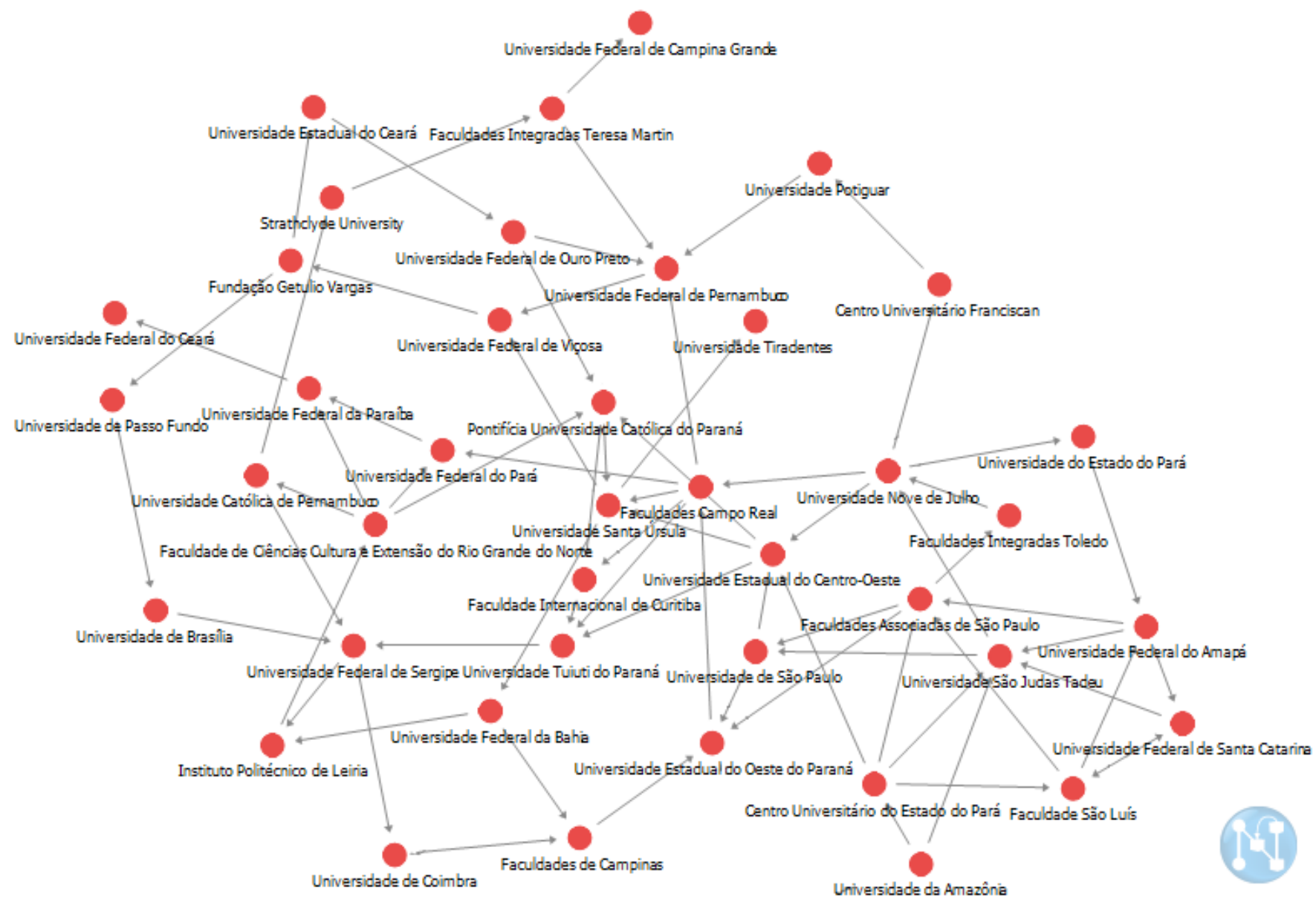

Fonte: Dados obtidos pelos autores, 2016.

Dos 71 artigos publicados no período analisado (2014 e 2015), 28 são frutos de acordos entre autores de universidades distintas.

Considerando-se as parcerias, ao todo foram 41 universidades analisadas. Dentre elas, é possível identificar as ligações fortes e fracas, tendo em vista os elementos de centralidade, que segundo Rossoni, Hocayen-da-Silva \& Ferreira Júnior (2008) se caracterizam por ter maior número de ligações. A quantidade de setas indicando as conexões também é um fator a ser levado em conta, sendo que quanto maior o número de flechas, mais densas são as conexões.

É possível analisar de forma mais clara ao observar o Quadro 3.

Quadro 3: Porcentagem das ligações.

\begin{tabular}{|l|c|}
\hline Número de ligações & Porcentagem \\
\hline Uma ligação & $39 \%$ \\
\hline Duas ligações (díade) & $29 \%$ \\
\hline Três ligações (tríade) & $22 \%$ \\
\hline
\end{tabular}




\begin{tabular}{|l|l|}
\hline Mais de três ligações & $10 \%$ \\
\hline
\end{tabular}

Fonte: Dados obtidos pelos autores, 2016.

Essa compilação permite inferir que a maioria dos elos formados em Secretariado Executivo é consistente. Juntas, as ligações mais influentes correspondem a $61 \%$ do total e verifica-se uma maior atuação no círculo acadêmico em que estão inseridas, possibilitando assim a difusão de ideias de forma mais eficaz. Entre as ligações mais fortes entre as instituições, destacam-se as que se ligam a mais de três universidades, sendo elas a Universidade São Judas Tadeu, a Universidade Federal de Pernambuco (UFPE) e a Universidade Estadual do Oeste do Paraná (UNIOESTE).

Da mesma forma, não se pode desconsiderar que $39 \%$ das publicações analisadas possuem ligações fracas, demonstrando potencial para integração e novas possibilidades no que tange a expansão da rede.

Esse fenômeno pode acontecer dentro ou fora dos grupos de pesquisa, gerando um grande estímulo ao compartilhamento de informações e percepções sobre determinado assunto. Quanto maior for a interação com a rede, maior será o conhecimento gerado, facilitando os caminhos para o aprendizado em conjunto. (Queiroz, Silva, \& Quandt, 2015).

Com esse mapeamento verifica-se que o potencial para o trabalho em parceria ainda é pouco aproveitado considerando a totalidade dos pesquisadores em Secretariado Executivo, mas os que já são membros da rede são mais propensos a participar ativamente. Com o fácil acesso aos meios de comunicação essa situação pode ser revertida, caso haja o interesse entre as partes.

Os grupos de pesquisa e as redes sociais possuem muitas semelhanças, já que partilham de um objetivo em comum: o de propiciar a troca de informações entre os pesquisadores fazendo com que o conhecimento seja criado de forma compartilhada e que possa agregar ideias de pessoas com experiências acadêmicas diferenciadas e com estilos de pesquisa distintos. Por meio de uma rede de cooperação científica, o homem ajuda o outro a se desenvolver e da mesma forma também se desenvolve. (Almeida, 2008)

Ao conectar pessoas que dividem ou não o mesmo ideal para a criação da cientificidade do Secretariado Executivo ou que pretendem aumentar os conhecimentos teóricos de uma determinada prática, um grande debate poderá ser colocado em vigor e, no futuro, problemas como falta de literatura na área podem ser amenizados. 


\section{CONSIDERAÇÕES FINAIS}

Esta pesquisa teve como intuito traçar um panorama sobre os grupos de pesquisa em Secretariado Executivo no Brasil e verificar a sua influência na construção do conhecimento da área. Além disso, a fim de complementar a pesquisa, foi feita uma investigação sobre as redes formadas entre os pesquisadores, com o propósito de conhecer as ligações existentes entre eles. A partir desses estudos foi possível ampliar a compreensão e promover debates sobre o tema.

A hipótese de que os grupos de pesquisa contribuem para a produção científica e que consequentemente ajudariam a consolidar a ciência, demonstrou-se verdadeira a partir da amostra utilizada. De acordo com as respostas obtidas pelos membros, eles ajudam sim a fazer com que aos poucos o número de produções científicas aumente, podendo assim embasar as atividades mais "técnicas" do Secretariado. Combinados à formação de parcerias entre os autores da mesma ou de universidades diferentes, a rede social tende a aumentar e a resultar no fortalecimento ou mesmo na criação de outros grupos de estudo, atraindo cada vez mais o interesse dos estudantes. Essas redes se mostraram ativas, mas ao mesmo tempo com atuação limitada. A grande maioria não as utiliza, mas os pesquisadores que decidem formar esses laços tendem a se conectar por mais vezes.

Da mesma forma, como dito por Nonato Júnior (2008), a área possui demandas intelectuais que precisam ser respondidas e, para que isso aconteça, é essencial que haja insumo tanto de pessoal, financeiro e intelectual. De acordo com as respostas analisadas, embora não seja um número expressivo, capaz de representar toda a população, verifica-se que ainda há uma carência de interessados em explorar cientificamente os assuntos que concernem à profissão. Os respondentes do questionário também levantaram a questão do auxílio financeiro escasso para a participação em eventos, demonstrando dificuldades em contribuir por parte dos órgãos mantenedores. E além disso, um fator desafiador é a falta da literatura adequada, exigindo criatividade do pesquisador para buscar em outras áreas, o que pode, por outro lado, se transformar em algo positivo, já que há um amplo espaço a ser explorado.

A bibliografia utilizada para este estudo ofereceu um bom aporte teórico, porém, na fase de coleta de dados foi encontrada certa dificuldade na obtenção de respostas para o questionário. Esse fator atua como limitante para um resultado mais fidedigno.

Assim, a função das redes sociais na construção do conhecimento de uma área que ainda necessita ser reconhecida como domínio científico é de extrema relevância. Por meio do 
compartilhamento de experiências, resultados e conhecimentos, um aprende com o outro e dessa forma a rede se fortalece. Com isso, auxilia-se não somente o dia a dia de um profissional atuante, mas também contribui com a formação do acadêmico e do pesquisador.

Para a conclusão deste trabalho é importante que haja uma reflexão do porquê a pesquisa científica em Secretariado Executivo continua por tanto tempo no "caminho das pedras", como designado por Maçaneiro e Kuhl (2013). Serão os fatores desmotivadores maiores do que a vontade em consolidar a profissão? Será que com a facilidade dos meios de comunicação os autores não possam se unir? Os grupos de pesquisa e as redes sociais são boas opções para serem colocadas em prática e impulsionar maiores realizações.

\section{REFERENCIAS}

Almeida, M. E. B. (2008). Tecnologia na escola: criação de redes de conhecimento. $\begin{array}{lllll}\text { Recuperado } & \text { em } & \text { janeiro, } & \text { de }\end{array}$ http://webeduc.mec.gov.br/midiaseducacao/material/introdutorio/popups/m1_e2_pop_ TecnologiaNaEscola.html.

Associação Brasileira de Pesquisa Secretariado. Recuperado em 4 junho, 2016, de http://www.abpsec.com.br/.

Bíscoli, F. R. V. \& Bilert, V. S. S. (2013). A evolução do Secretariado Executivo: caminhos prováveis a partir dos avanços da pesquisa científica e dos embates teóricos e conceituais na área. Revista Expectativa, vol. 12, n. 12, pp. 9-42.

Brasil. Conselho Nacional de Pesquisa. Grupos de Pesquisa. Recuperado em 25 janeiro, 2016, de http://www.cnpq.br/diretóriodosgruposdepesquisa5

Campos, F. G. G.; Santos, R. F. \& Santos, F. C. P. (2009). A importância da pesquisa científica na formação profissional dos alunos do curso de educação física do Unilestemg. Movimentum - Revista digital de Educação Física, Ipatinga: UnilesteMG, vol. 4, n. 2. 
Corbin, J. \& Strauss, A. (2015). Basics of Qualitative Research: Techniques and Procedures for Developing Grounded Theory (4a ed.). Sage Publications.

Duarte, T. (2009). A possibilidade da investigação a 3: reflexões sobre triangulação (metodológica). Lisboa, Portugal: CIES e-Working Papers.

Durante, D. G. (2010). Tópicos especiais em técnicas de secretariado. Curitiba: IESD.

Durante, D. G. (2012). A evolução da profissão secretarial por meio da pesquisa. Pesquisa em Secretariado: cenários, perspectivas e desafios. Passo Fundo: UPF Editora.

Durante, D. G. \& Pontes, E. S. (2015). Produção intelectual em Secretariado Executivo: Estudo na revista de Gestão e Secretariado (GeSec). Revista de Gestão e Secretariado - GeSec, vol. 6, n. 1, pp. 23-47.

Freitas, H.; Oliveira. M.; Saccol, A. Z. \& Moscarola, J. (2000). O método de pesquisa survey. Revista de Administração, São Paulo, vol. 35, n. 3, pp. 105-112.

Garcia, R.; Araújo, V.; Mascarini, S.; Santos, E. G. \& Costa, A. R. (2014). Interações universidade-empresa e a influência das características dos grupos de pesquisa acadêmicos. Revista de Economia Contemporânea, vol. 18, n. 1, pp. 125-146.

Gerhardt, T. E. \& Silveira, D. T. (2009). Métodos de Pesquisa. Porto Alegre: Editora da UFRGS.

Gil, A. C. (2007). Métodos e técnicas de pesquisa social (5a ed.). São Paulo: Atlas.

Granovetter, M. S.; (1973). The Strength of Weak Ties. American Journal of Sociology, vol. 78, n. 6. 
Gunther, H. (2003). Como elaborar um questionário (Série: Planejamento de Pesquisa nas Ciências Sociais, n. 1). Brasília, DF: UnB, Laboratório de Psicologia Ambiental.

Hoeller, P. A. F. (2006). A natureza do conhecimento em Secretariado Executivo. Revista Expectativa, vol. 5, n. 5.

Krahl, M.; Sobiesiak, E. F.; Poletto, D. S.; Casarin, R. G.; Knopf, L. A.; Carvalho, J. \& Motta, L. A. (2009). Experiência dos acadêmicos de enfermagem em um grupo de pesquisa. Revista Brasileira de Enfermagem, vol. 63, n. 1, pp. 146-150.

Lima, K. K. \& Amaral, D. C. (2008). Práticas de gestão do conhecimento em grupos de pesquisa da rede Instituto Fábrica do Milênio. Revista Gest. Prod., vol. 15, n, 2, pp. 291-205.

Lordêlo, P. \& Sá, K. (2015). Um retrato dos grupos de pesquisa da fisioterapia e terapia ocupacional no Brasil. Revista Pesquisa em Fisioterapia, vol. 5, n. 1, pp. 4-6.

Maçaneiro, M. B. \& Kuhl, M. R. (2013). Estado da arte e o rumo do conhecimento científico em Secretariado Executivo: Mapeamento e análise de áreas de pesquisa. Revista de Gestão e Secretariado - GeSec, vol. 4, n. 3, pp. 157-188.

Maia, M. F. \& Caregnato, S. E. (2008). Coautoria como indicador de redes de colaboração científica. Perspectivas em Ciência da Informação, vol. 13, n. 2, p. 18-31.

Marafon, G. J. (2008). A importância dos grupos de pesquisa na formação dos profissionais de geografia agrária: a experiência do NEGEF1. Campo-Território: Revista de Geografia Agrária, vol. 3, n. 5, pp. 284-290.

Mattar, F. N. (2005). Pesquisa de marketing: metodologia, planejamento (6a ed.). São Paulo: Atlas. 
Morosini, M. C. (2006). Enciclopédia de Pedagogia Universitária. Glossário, vol. 2.

Nascimento, S. \& Beureu, I, M. (2011). Redes Sociais na produção científica dos programas de pós-graduação de Ciências Contábeis do Brasil. RAC, Curitiba, vol. 15, n. 1, art. 3, pp. 47-66.

Nonato Júnior, R. (2011). A gestão dos recursos da informação nas ciências sociais aplicadas: uma abordagem para Secretariado Executivo. Revista Capital Científico, vol. 5 , n. 1 .

Nonato Júnior, R. (2008). Epistemologia do Secretariado Executivo: por uma teoria do conhecimento em Secretariado. In: XVI Congresso Nacional de Secretariado. Anais (Resumos). Brasilia: Federação Nacional de Secretariado, pp. 7-8.

Nonato Júnior, R. (2009). Epistemologia e teoria do conhecimento em Secretariado Executivo: a fundação das Ciências da Assessoria. Fortaleza: Expressão Gráfica.

Odelius, C. C. \& Sena, A. C. (2009). Atuação em grupos de pesquisa: competências e processos de aprendizagem. Faces Journal, vol. 8, n. 4.

Pereira, I. A.; Moreira, N. C. \& Baeta, O. V. (2012). Fatores motivacionais para pesquisa na área de Secretariado Executivo das IFES brasileiras. Revista Sociais e Humanas, ed. 1, vol. 25, pp 140-155.

Piaget, J. (2002). Epistemologia genética (2a ed.). São Paulo: Martins Fontes, 2002.

Pivetta, H. M. F.; Backes, D. S.; Carpes, A.; Battistel, H. T. \& Marchiori, M. (2010). Ensino, Pesquisa e Extensão Universitária: em busca de uma integração efetiva. Linhas Críticas, vol. 16, n. 31, pp. 377-90. 
Queiroz, F. C. B. P.; Silva, H. F. N. \& Quandt, C. O. (2015). Formas de compartilhamento de informações e do conhecimento na cooperação internacional de pesquisadores. Inf. \& Soc.: Est., João Pessoa, vol. 25, n.3, pp. 147-161.

Rossoni, L.; Hocayen-Da-Silva, A. J \& Ferreira Júnior, I. (2008). Aspectos estruturais da cooperação entre os pesquisadores no campo de administração pública e gestão social: análise das redes entre instituições no Brasil. Revista de Administração Pública, vol. 42, n. 6.

Sabino, R. F. \& Marchelli, P. S. (2009). O debate teórico-metodológico no campo do secretariado: pluralismos e singularidades. Cad. Ebape.BR, Rio de Janeiro, vol. 7, $\mathrm{n}$. 4, pp. 607-621.

Schmidt; C. M.: Cielo, I. D. \& Sanches, F. C.; (2011). Mapeamento das relações entre universidades e docentes: um estudo de redes em cursos de Secretariado Executivo. A evolução da profissão por meio da pesquisa. Universidade de Passo Fundo, Passo Fundo.

Soler, L. (2009). Introduction à l'épistémologie. Ellipses, p. 335. Recuperado em 25 junho, 2016, de https://hal.archives-ouvertes.fr/halshs-00512386/.

Souza, F. C. et al. (2008). Investigação das instituições de ensino e de seus pesquisadores a partir da produção científica da Revista Contabilidade \& Finanças. In: XV Congresso Brasileiro de Custos, 15. Curitiba: Paraná.

Werneck, V. R. (2006). Sobre o processo de construção do conhecimento: O papel do ensino e da pesquisa. Ensaio: aval. Pol. Públ. Educ., vol. 14, n. 51, pp. 173-196, 2006. 